Abstract

\title{
Application Runs the Show: What Can We Learn about the Future from the Past? ${ }^{\dagger}$
}

\author{
Nicolae Barsan \\ Institute of Physical Chemistry, University of Tuebingen, Auf der Morgenstelle 15, \\ D-72076 Tuebingen, Germany; nb@ipc.uni-tuebingen.de \\ + Presented at the 8th GOSPEL Workshop. Gas Sensors Based on Semiconducting Metal Oxides: \\ Basic Understanding \& Application Fields, Ferrara, Italy, 20-21 June 2019. \\ Published: 21 June 2019
}

\section{History and Current Status}

SMOX-based sensors appeared as a response to a very serious safety issue in Japan, namely gas explosion accidents related to leakages of piped and bottled cooking gas. The first commercial gas sensors were self-supported beads; there were two Pt coils, one of them used as heater and with a DC resistance measurement between the two coils. The power consumption was more than $1 \mathrm{~W}$ [1].

SMOX-based sensors application fields were extended because of their inherent advantages-high sensitivity, low cost, good stability-and as a consequence the performance requirements evolved. At the beginning of the 1990s, the regulation of the air intake for car cabins was becoming extremely important and, because of cost issues, the miniaturization drive was gaining practical relevance [2]. Together with the additional trend of getting all household devices battery operated [3], the resulting market pull determined the appearance of the current state of the art gas sensors that are realized by depositing porous sensing layers realized by using pre-processed powders onto ceramic and MEMS substrates [4,5].

\section{Future Trends}

As in the past, the developments in the field are determined by the needs of the applications to be solved. Shifting from mains connected domestic gas alarms to battery operated ones will surely continue as will continue the integration of more sensors with the target to detect more gases and provide extended functionality such as fire detection and/or indoor air quality. There are already commercial devices that use SMOX gas sensors for the latter; they measure the total volatile organic compounds TVOC concentration and are giving a $\mathrm{CO}_{2}$ equivalent output [6]. One can imagine that success in this field will make possible the large scale integration of SMOX sensors in a host of household products with the biggest prize being the integration into mobile devices such as smart phones. There are companies that are making this approach quite central to their development strategy [7]. There are also reports about successful integration of SMOX sensors in cooking hoods as fire alarms [8].

Another type of applications that are rising a lot of interest are the ones related to breath analysis, especially for the detection of diseases [9]. It was proven that it is possible to use gas sensors for measuring the NO content of alveolar air and by that to get important information about inflammatory processes in the lungs and adjust medication [10]; there are though a couple of caveats: the used gas sensor is a highly specific electrochemical cell and the sampling technique increases the complexity and the price of the instrument. Moreover, the application it serves is really well documented and even standardized [11]. Such a success is not easy to emulate because one of the intrinsic weaknesses of the SMOX sensors is their lack of selectivity. This is the reason why a lot of efforts are made for obtaining selective sensors and it is expected that this will be one of the main direction for the future R\&D activities. 
In what concerns the transducers, besides the approach towards miniaturization of the MEMS substrates it is expected that activities focused on the use of additives technologies and plastics will amplify with the goal of decreasing even more the costs of the gas sensors to such an extent that disposable devices will be available [2]. It was already shown that it is possible to integrate different sensing principles on foils [12] - the various transducers were obtained by using MEMS, which is a non-additive technology-so the next steps will be in the direction of developing processes compatible to roll to roll production. Such transducers will need sensing layers deposition methods that do not require high temperatures annealing.

One can conclude that, because of the application pull, the drive is towards further miniaturization, see Figure 1, and increased selectivity and sensitivity in order to make possible their integration in a host of mobile and household devices and help make possible the Internet of Things (IoT).

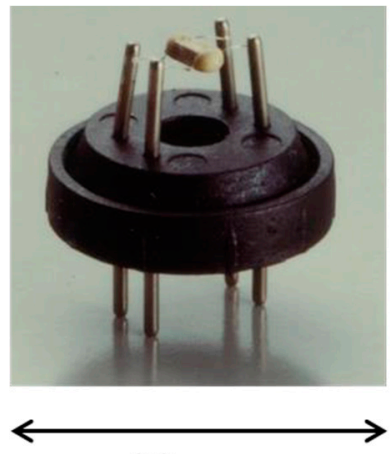

$22 \mathrm{~mm}$

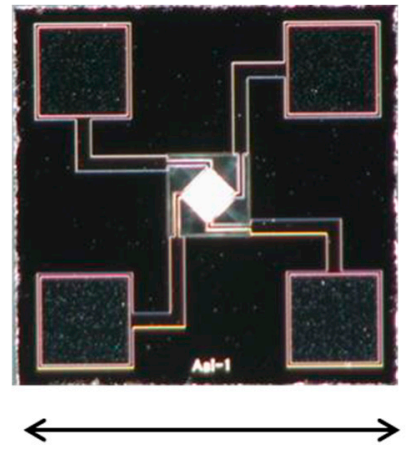

$1 \mathrm{~mm}$

Figure 1. First and last generation of methane Figaro gas sensors (courtesy of Figaro Eng.).

\section{References}

1. Ihokura, K.; Watson, J. Stannic Oxide Gas Sensors, Principles and Applications; CRC Press: Boca Raton, FL, USA; Ann Arbor, MN, USA; London, UK; Tokyo, Japan, 1994; 187p.

2 Briand, D.; Courbat, J. Micromachined Semiconductor Gas Sensors. In Semiconductor Gas Sensors; Jaaniso, R., Tan, O.K., Eds.; Woodhead Publishing Series in Electronic and Optical Materials; Woodhead Publishing Limited: Oxford, UK; Cambridge, UK; Philadelphia, PA, USA; New Delhi, India, 2013; Chapter 6, pp. 220-260.

3. Tanihira, T.; Yoshioka K.; Shinnishi, K.; Izawa, K.; Kaneyasu, K..; Development of $\mathrm{CH}_{4}$ Sensor Using MEMS Technology for Battery Operated Town Gas Leak Detector. Sens. Lett. 2011, 9, 414-417.

4. Simon, I.; Barsan, N., Weimar, U., Bauer, M, Micromachined metal oxide gas sensors: opportunities to improve sensor performance. Sens. Actuators B 2001, 73, 1-26.

5. Available online: https://www.fujielectric.com/company/research_development/theme/mems_sensor.html (accessed on 1 May 2019).

6. Available online: http://ams.com/eng/Products/Chemical-Sensors/Air-Quality-Sensors (accessed on 1 May 2019).

7. Available online: https:/www.sensirion.com/en/environmental-sensors/gas-sensors/ (accessed on 1 May 2019).

8. Ulmer, H. Application of MEMS MOS Gas Sensors in Everyday Life: From Cars to Cooker hoods. In Proceedings of the 4th GOSPEL Workshop on: Gas Sensors Based on Semiconducting Metal Oxides: Basic Understanding \& Applications, Tuebingen, Germany, 6-7 June 2011.

9. Di Natale C, Paolesse R, Martinelli E, Capuano R; Solid-state gas sensors for breath analysis: A review. Anal. Chim. Acta 2014, 824, 1-7.

10. Available online: https://www.niox.com/en/ (accessed on 1 May 2019). 
11. Available online: https://www.atsjournals.org/doi/10.1164/ajrccm.160.6.ats8-99 (accessed on 1 May 2019).

12 Oprea, A.; Courbat, J.; Briand, D.; Barsan, N.; Weimar, U.; De Rooij, N.F. Environmental monitoring with a multisensor platform on polyimide foil. Sens. Actuators B 2012, 171-172, 190-197.

(c) (1)

(C) 2019 by the authors. Licensee MDPI, Basel, Switzerland. This article is an open access article distributed under the terms and conditions of the Creative Commons Attribution (CC BY) license (http://creativecommons.org/licenses/by/4.0/). 